\title{
YEARS OF LIFE LOST DUE TO PREMATURE MORTALITY IN A PROVINCE WITH THE SHORTEST LIFE EXPECTANCY IN POLAND
}

\author{
Marek Bryła1, Małgorzata Pikala², Irena Maniecka-Bryła² \\ ${ }^{1}$ Social Medicine Department, Medical University of Lodz, Lodz, Poland \\ 2Epidemiology and Biostatistics Department, Medical University of Lodz, Lodz, Poland
}

\section{SUMMARY}

Aim: The aim of the study was to evaluate years of life lost for citizens of the Lodz Province, which is characterized by the lowest life expectancy in Poland, and to identify current trends in this area according to the most common causes of death.

Methods: The study material included a database containing information gathered from 470,000 death certificates of Lodz Province inhabitants, who died between 1999 and 2011. In order to calculate years of life lost, the authors applied the SEYLL (Standard Expected Years of Life Lost per living person) and $\mathrm{SEYLL}_{d}$ (per death) indices. The analysis of time trends was carried out with the application of joinpoint models.

Results: The SEYLL measure was 2,300 years per 10,000 males and 1,500 years per 10,000 females in 2011. Cardiovascular diseases contributed to the highest number of years of life lost (SEYLL $=682$ years per 10,000 males and 559 years per 10,000 females). Next were malignant neoplasms ( $S E Y L L_{p}=505$ years per 10,000 males and 437 years per 10,000 females), external causes of death ( $S E Y L L_{p}=361$ years per 10,000 males and 83 years per 10,000 females). The number of years of life lost due to acute myocardial infarction decreased most rapidly, the Annual Percent Change (APC) was $-10.1 \%$ in males and $-3.7 \%$ in females. However, heart failure contributed to the highest increase in the number of years of life lost (APC $=10.8 \%$ in males and $10.9 \%$ in females).

Conclusions: A further decrease in the mortality rate due to cardiovascular diseases might contribute to the highest reduction of years of life lost. The most effective preventive activities are those aimed at reducing productive years of life lost due to a particular cause of death, i.e. road traffic accidents, suicides, cirrhosis of the liver, alcoholic liver disease, and malignant neoplasms of the trachea, bronchi and lungs.

Key words: standard expected years of life lost, premature mortality, burden of disease, Lodz province, Poland

Address for correspondence: I. Maniecka-Bryła, Epidemiology and Biostatistics Department, Medical University of Lodz, Żeligowskiego Str. 7/9, 90-742 Lodz, Poland. E-mail: irena.maniecka-bryla@umed.lodz.pl

http://dx.doi.org/10.21101/cejph.a4289

\section{INTRODUCTION}

The economic transformation which occurred in Poland after 1989 substantially influenced lifestyle and health behaviours of Polish society (1-4). The development of new medical technologies and modern diagnostic methods have improved many aspects of health: for example, a decrease in the death rate led to an increase in average life expectancy. The life expectancy of the inhabitants of Poland has been continuously increasing since 1991. In 2011, the average life expectancy was 72.4 years for males and 80.9 years for females (5). Despite these positive changes, the health condition of the Polish population is much worse than the one observed in most European countries. Out of a group of 47 countries, Poland occupies position in the third ten: 30th position for males and 27th position for females (6-7).

The above mentioned relatively positive health trends are average changes. A more thorough analysis of health measures confirms huge differences in the average life expectancy between particular provinces. This is especially apparent in the Lodz Province since the life expectancy of its inhabitants is the shortest in the country: the average life expectancy in 2011 in the Lodz
Province was only 70.5 years for males, i.e. 3.8 years shorter than in the Podkarpackie Province, where the male life expectancy is the longest, and 79.7 years for females, 3.8 years shorter than in the Podkarpackie and Podlaskie Provinces.

Different definitions of premature mortality exist in epidemiological research. Assuming an economic criterion according to which premature death is that which happens before the age of 65, premature deaths in 2011 made up 19\% of the total number of deaths in the European Union, $29.3 \%$ in Poland and $30.5 \%$ in the Lodz Province (8). The immediate result of premature mortality is the number of years lost for the population of Poland. Measures used for calculating mortality in units of lost time are favoured because they are more reliable in showing the economic and social impact of loss connected with premature mortality better than other commonly used measures (9-14). From the economic point of view, the most effective preventive activities are those aimed at reducing the greatest number of years of life lost.

The aim of the study was to evaluate the number of years of life lost for inhabitants of the Lodz Province in the period of 1999-2011 and identify current trends with regard to the most common causes of death. In the future, this might allow the de- 
termination of factors contributing to premature mortality in the province and development of preventive measures to eliminate inequalities between the Lodz Province and other provinces in Poland.

\section{MATERIALS AND METHODS}

The study material included a database containing information gathered from 470,097 death certificates of the inhabitants of the Lodz Province who died between 1 January 1999 and 31 December 2011. The information was disclosed by the Information Department of the Main Statistical Office. The given number refers to all deaths of Lodz inhabitants which happened in the 13-year study period.

The SEYLL measure (Standard Expected Years of Life Lost) is used to calculate the number of years of life lost for the studied population in comparison to the years lost by the referential (standard) population. Life tables of the 15 'old' European Union member states were adopted as standard (15). Based on a population of size $N$ and with $d_{x c}$ standing for the number of deaths at the age of $x$ due to a particular cause $c, e_{x}^{*}$ is the number of expected years of life that remain to be lived by the population which is at the age of $x$. Assuming that $l$ is the last year of age until which the population lives, the number of years of life lost due to the cause $c$ is calculated with the use of the following formula:

$$
S E Y L L=\sum_{x=0}^{l} d_{x c} e_{x}^{*}
$$

By dividing the absolute number of years lost due to cause $c$, calculated according to the following formula, by the number of deaths due to cause $c$, the average number of years of life lost by one person who died due to cause $c$ can be calculated.

$$
\text { SEYLL } L_{d}=\frac{\sum_{x=0}^{l} d_{x c} e_{x}^{*}}{\sum_{x=0}^{l} d_{x c}}
$$

The authors also estimated the SEYLL indices determined by the number of the studied population.

$$
\operatorname{SEYLL}_{p}=\frac{\sum_{x=0}^{l} d_{x c} e_{x}^{*}}{N}
$$

The analysis of time trends has been carried out with joinpoint models. The Joinpoint Regression Program is a statistical software package developed by the U.S. National Cancer Institute for the Surveillance, Epidemiology and End Results Program. The software takes trend data and fits the simplest joinpoint model that the data allow. The user supplies the minimum and maximum number of joinpoints. The program starts with the minimum number of joinpoints (e.g. 0 joinpoints, which is a straight line) and tests whether more joinpoints are statistically significant and must be added to the model (up to that maximum number). This enables the user to test whether an apparent change in trend is statistically significant $(\mathrm{p}<0.05)$. The tests of significance use the Monte Carlo Permutation method. The software also allows the creation of graphs where several different lines are connected together at the joinpoints (16). Annual percentage change (APC) was also calculated for the SEYLL ${ }_{\mathrm{p}}$ and SEYLL $\mathrm{d}_{\mathrm{d}}$ indices for each segment of broken lines.

\section{RESULTS}

The absolute number of years of life lost for the inhabitants of the Lodz Province in 2011 was higher than 480,000 (280,000 males and 200,000 females): 2,300 years per 10,000 males and 1,500 years per 10,000 females. In the male group, the SEYLL measure fell between 1999 and 2003 at an average APC of $-0.6 \%$.

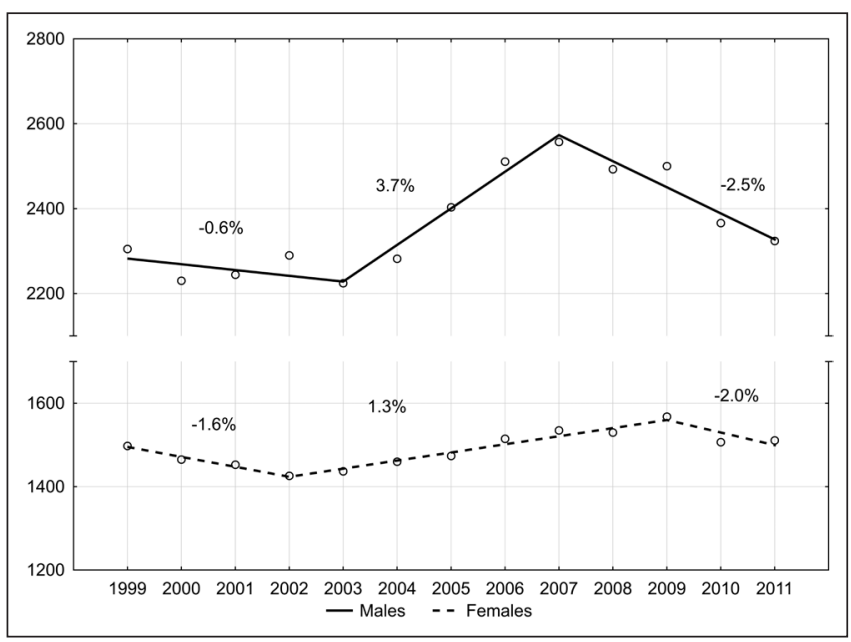

Fig. 1. Time trends in SEYLL ${ }_{p}$ in the Lodz Province during the period from 1999-2011 (per 10,000 people).

Table 1. Standard expected years of life lost per 10,000 people (SEYLL $)$ and structure by causes of death in the Lodz Province in 2011

\begin{tabular}{|l|c|c|c|c|}
\hline \multirow{2}{*}{ Cause of death } & \multicolumn{2}{|c|}{ Males } & \multicolumn{2}{c|}{ Females } \\
\cline { 2 - 5 } & SEYLL $_{p}$ & $\%$ & SEYLL $_{p}$ & 359 \\
\hline Diseases of the circulatory system (I00-199) & 682 & 29.7 & 437 & 29.1 \\
\hline Malignant neoplasms (C00-C97) & 505 & 22.0 & 83 & 5.5 \\
\hline External causes of death (V01-Y98) & 361 & 15.7 & 69 & 4.6 \\
\hline Diseases of the digestive system (K00-K93) & 117 & 5.1 & 61 & 4.1 \\
\hline Diseases of the respiratory system (J00-J99) & 90 & 3.9 & 291 & 19.4 \\
\hline Other & 545 & 23.6 & & 2 \\
\hline
\end{tabular}


After 2003, it increased at a rate of 3.7\%, but started to decrease again at an average APC of $-2.5 \%$ after 2007 . In the female group, the SEYLL $\mathrm{p}_{\mathrm{p}}$ measure fell from 1999 to $2002(\mathrm{APC}=-1.6 \%)$, then increased from 2002 to 2009 ( $\mathrm{APC}=1.3 \%$ ). However, since that time, the number of years of life lost has been decreasing at an annual percentage change of $-2.0 \%$ (Fig. 1).

Cardiovascular diseases contributed to the greatest number of years of life lost. In 2011, this class of diseases was responsible for the loss of 682 years per 10,000 males (29.7\%) and 559 years per 10,000 females $(37.3 \%)$. The second most common cause of death, i.e. malignant neoplasms, contributed to the loss of 505 years of life per 10,000 males (22\%) and 437 years per 10,000 females $(29.1 \%)$. External causes of death were responsible for the $15 \% \mathrm{SEYLL}_{\mathrm{p}}$ measure in the male group (361 years per 10,000 males) and $5.5 \% \mathrm{SEYLL}_{\mathrm{p}}$ measure in the female group (83 years per 10,000 females). Diseases of the digestive system caused the loss of 117 years per 10,000 males (5.1\%) and 69 years per 10,000 females $(4.6 \%)$. With regards to diseases of the respiratory system, the values were 90 and 61 years per 10,000 males and females and the percentage was 3.9 and 4.1, respectively (Table 1). When comparing the value of SEYLL measure by causes of death with the proportional mortality rate (Fig. 2), it can be seen that cardiovascular diseases contribute to a relatively small number of years of life lost. It can be concluded that many deaths due to this group of diseases were of the elderly, hence, the number of years of life lost was not so high. The percentage of years of life lost due to external causes was much higher than the proportional mortality rate for this class of causes, particularly in males. It should be pointed out that in the group of females the contribution of malignant neoplasms to the loss of years of life is higher than the proportional mortality rate.

A more detailed analysis of the SEYLL $\mathrm{p}_{\mathrm{p}}$ measure by the most common causes of death shows that in the male group, the greatest loss in the number of years of life is caused by heart failure (182.6 years per 10,000 males), ischaemic heart disease (162.4 years per 10,000 males), cerebrovascular diseases (160.3 years per 10,000 males), malignant neoplasms of the trachea, bronchus and lung (157.6 years per 10,000 males), and suicide ( 117.3 years per 10,000 males). Further positions (less than 100 years of life lost per 10,000 males) are occupied by road traffic accidents,

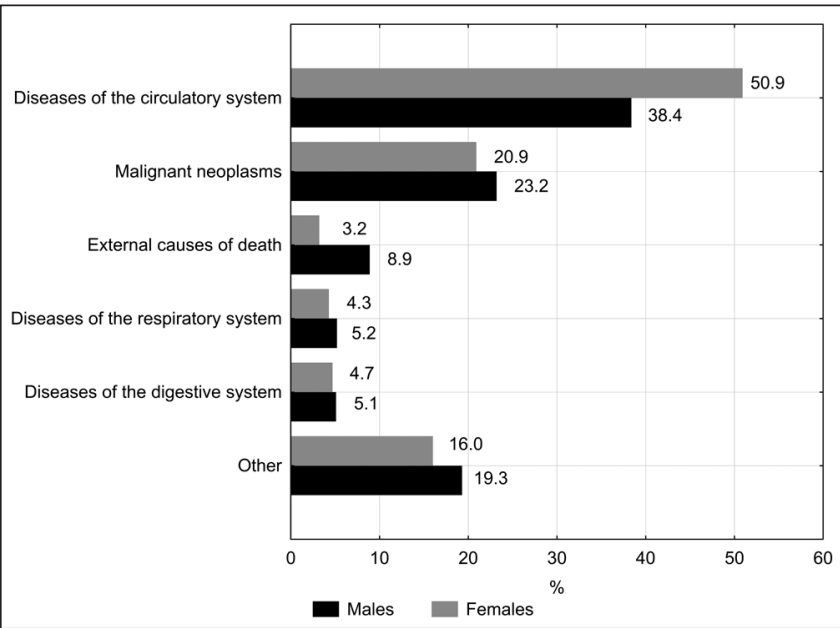

Fig. 2. Proportion of the most common causes of death, the Lodz Province, 2011. cirrhosis of the liver, alcoholic liver disease and diseases of the arteries, arterioles and capillaries - mainly including atherosclerosis (Table 2). The highest values of the SEYLL indices for the given causes of death result from their high incidence. This is confirmed by comparison of their ranks with the ranks for the SEYLL $_{d}$ indices calculated as the ratio of the number of years of life lost due to a particular reason to the number of people who died for this reason. When such a criterion is applied, it can be seen that traffic accidents contributed to the highest number of years of life lost. Males who died in traffic accidents in 2011 lost on average 35.7 years of life. Suicide took the second position contributing to the loss of 33.6 years of life. Further positions were taken by cirrhosis of the liver and alcoholic liver disease (25.9 years), malignant neoplasm of pancreas (18.2 years), and malignant neoplasms of the trachea, bronchus and lung (17.1 years). The most common causes from the class of cardiovascular diseases ranked 1st and 2nd in the SEYLL $\mathrm{p}_{\mathrm{p}}$ classification, i.e. heart failure and ischaemic heart disease, took only the 9th and the 8th positions. They contribute to a loss of 14.3 and 14.4 years of life per one male death, respectively.

With regards to females, the most years of life lost were related to cerebrovascular diseases (152.2 years per 10,000 females), heart failure (136.1 years per 10,000 females), ischaemic heart disease (103.6 years per 10,000 females), diseases of arteries, arterioles and capillaries (83.5 years per 10,000 females), malignant neoplasms of the trachea, bronchus and lung ( 73.8 years per 10,000 females), as well as breast cancer (63.8 years per 10,000 females). As in the male group, the ranks of particular causes of death varied greatly. The highest number of years of life lost was caused by traffic accidents (on average 36.4 years), suicide (30.8 years), cirrhosis and alcoholic liver disease (29.4 years), malignant neoplasms of the cervix (24.2 years), ovary (22.7 years) and breast (21.1 years), as well as malignant neoplasms of the trachea, bronchus and lung (21 years each). Cardiovascular diseases, which contributed to the highest number of years of life lost per 10,000 females, contributed to less serious losses when calculated per one female who died due to these diseases: 11.0 years for cerebrovascular diseases (13th position), 9.7 years for heart failure (15th position), 10.9 years for ischaemic heart disease (14th position), and 7.1 years for diseases of the arteries, arterioles and capillaries (16th position).

The analysis of trends of years of life lost indicates that the most negative changes referred to heart failure. The SEYLL $L_{p}$ measure rose at an average annual percentage change of $10.8 \%$ in the male group and $10.9 \%$ in the female group in the period 2002-2011 $(p<0.05)$. In the group of males, a significant increase in years of life lost due to suicide was also observed with regard to SEYLL measure $(\mathrm{APC}=1.4 \%, \mathrm{p}<0.05)$, while a negative trend of years of life lost due to tracheal, bronchial and lung malignant neoplasms can be observed in the female group (APC $=3.1 \%, p<0.05$ ).

The most positive changes referred to the number of years of life lost both in males and females due to ischaemic heart disease, including acute myocardial infarction: $\mathrm{APC}=-10.1 \%(\mathrm{p}<0.05)$ in the male group in $2007-2011, \mathrm{APC}=-3.7 \%(\mathrm{p}<0.05)$ in the female group in 1999-2011. Both groups displayed a significant decrease in the rate of years of life lost due to cerebrovascular diseases, diseases of arteries, arterioles and capillaries (foremost atherosclerosis), malignant neoplasm of stomach, influenza and pneumonia. The SEYLL $\mathrm{p}_{\mathrm{p}}$ measure decreased in the male and 
Table 2. Standard expected years of life lost per 10,000 people (SEYLL $)_{p}$ and per the number of deaths (SEYLL $\left.{ }_{d}\right)$ by the most common causes in the Lodz Province in 2011

\begin{tabular}{|c|c|c|c|c|}
\hline Cause of death & SEYLL $_{p}($ per 10,000) & SEYLL $_{p}$ rank & SEYLL $_{d}$ & SEYLL ${ }_{d}$ rank \\
\hline \multicolumn{5}{|l|}{ Males } \\
\hline Heart failure $(150)$ & 182.6 & 1 & 14.3 & 9 \\
\hline Ischaemic heart diseases (I20-|25) & 162.4 & 2 & 14.4 & 8 \\
\hline Cerebrovascular diseases (160-169) & 160.3 & 3 & 13.9 & 10 \\
\hline Malignant neoplasms of trachea, bronchus and lung (C33, C34) & 157.6 & 4 & 17.1 & 5 \\
\hline Intentional self-harm (X60-X84) & 117.3 & 5 & 33.6 & 2 \\
\hline Transport accidents (V01-V99) & 80.9 & 6 & 35.7 & 1 \\
\hline Fibrosis and cirrhosis of liver and alcoholic liver disease (K70, K74) & 79.1 & 7 & 25.9 & 3 \\
\hline Diseases of arteries, arterioles and capillaries (170-179) & 61.1 & 8 & 8.7 & 14 \\
\hline Malignant neoplasm of colon (C18) & 51.4 & 9 & 14.6 & 7 \\
\hline Influenza and pneumonia (J10-J18) & 46.8 & 10 & 13.9 & 11 \\
\hline Chronic lower respiratory diseases (J40-J47) & 36.7 & 11 & 12.2 & 12 \\
\hline Malignant neoplasm of stomach (C16) & 32.6 & 12 & 16.5 & 6 \\
\hline Malignant neoplasm of pancreas (C25) & 24.5 & 13 & 18.2 & 4 \\
\hline Malignant neoplasm of prostate (C61) & 23.8 & 14 & 11.3 & 13 \\
\hline \multicolumn{5}{|l|}{ Females } \\
\hline Cerebrovascular diseases (160-169) & 152.2 & 1 & 11.0 & 13 \\
\hline Heart failure $(150)$ & 136.1 & 2 & 9.7 & 15 \\
\hline Ischaemic heart disease (I20-|25) & 103.6 & 3 & 10.9 & 14 \\
\hline Diseases of arteries, arterioles and capillaries (170-179) & 83.5 & 4 & 7.1 & 16 \\
\hline Malignant neoplasms of trachea, bronchus and lung (C33, C34) & 73.8 & 5 & 21.0 & 7 \\
\hline Malignant neoplasms of breast (C50) & 63.8 & 6 & 21.1 & 6 \\
\hline Malignant neoplasm of colon (C18) & 43.7 & 7 & 15.6 & 9 \\
\hline Fibrosis and cirrhosis of liver and alcoholic liver disease (K70, K74) & 39.2 & 8 & 29.4 & 3 \\
\hline Influenza and pneumonia (J10-J18) & 33.5 & 9 & 11.7 & 12 \\
\hline Malignant neoplasms of ovary (C56) & 31.4 & 10 & 22.7 & 5 \\
\hline Malignant neoplasms of cervix uteri (C53) & 25.2 & 11 & 24.2 & 4 \\
\hline Transport accidents (V01-V99) & 24.5 & 12 & 36.8 & 1 \\
\hline Chronic lower respiratory diseases (J40-J47) & 23.0 & 13 & 14.2 & 11 \\
\hline Malignant neoplasm of pancreas (C25) & 18.8 & 14 & 15.4 & 10 \\
\hline Malignant neoplasm of stomach (C16) & 14.7 & 15 & 16.3 & 8 \\
\hline Intentional self-harm (X60-X84) & 14.4 & 16 & 30.8 & 2 \\
\hline
\end{tabular}

female groups, particularly with regard to traffic accidents for males, and to malignant neoplasms of the cervix, pancreas and colon for females (Table 3).

\section{DISCUSSION}

Cardiovascular diseases still contribute to the highest number of years of life lost as calculated per number of inhabitants of a particular province. However, a regular drop in mortality due to cardiovascular diseases resulting from a decrease in the number of deaths caused by ischaemic heart disease has been observed in the Lodz Province, as in the rest of Poland and other European countries (17-21). A study on mortality rates due to ischaemic heart disease conducted in seven European countries (The Netherlands,
Great Britain, France, and four Scandinavian countries) found that if this fall remains constant, the mortality rate for this reason in 2030 will be $50 \%$ that of 2005 (22). However, the number of years of life lost due to ischaemic heart disease is known to be increasing, which confirms the presence of a close relationship between mortality caused by ischaemic heart disease and heart failure. Heart failure is a final stage of cardiac damage caused by various diseases. Progress in treating acute coronary syndrome contributed to better prognosis but first of all, to a significant decrease in the number of deaths in acute myocardial infarction. Many patients survive this incident but they develop heart failure as a result of extensive cardiac damage. Paradoxically, improvement in diagnostics and treatment of cardiovascular diseases, particularly ischaemic heart disease and arterial hypertension, leads to an increase in the morbidity of heart failure (23). 
Table 3. Annual percentage change of SEYLL ${ }_{p}$ per 10,000 people due to the most common causes of death in inhabitants of the Lodz Province in 1999-2011

\begin{tabular}{|c|c|c|c|c|}
\hline \multirow{2}{*}{ Cause of death } & \multicolumn{2}{|c|}{ Males } & \multicolumn{2}{|c|}{ Females } \\
\hline & Years & APC & Years & APC \\
\hline \multirow{3}{*}{ Ischaemic heart diseases (|20-|25) } & 1999-2004 & $-3.9^{*}$ & \multirow{3}{*}{ 1999-2011 } & \multirow{3}{*}{$-1.5^{\star}$} \\
\hline & $2004-2007$ & 2.4 & & \\
\hline & $2007-2011$ & $-7.2^{*}$ & & \\
\hline \multirow{3}{*}{ Including: acute myocardial infarction (I21) } & 1999-2004 & $-7.0^{*}$ & \multirow{3}{*}{ 1999-2011 } & \multirow{3}{*}{$-3.7^{*}$} \\
\hline & $2004-2007$ & 3.3 & & \\
\hline & 2007-2011 & $-10.1^{*}$ & & \\
\hline \multirow{2}{*}{ Cerebrovascular diseases (160-169) } & 1999-2008 & -0.2 & 1999-2007 & -0.4 \\
\hline & 2008-2011 & $-6.7^{*}$ & $2007-2011$ & $-5.9^{*}$ \\
\hline Diseases of arteries, arterioles and capillaries (170-179) & 1999-2011 & $-3.8^{*}$ & 1999-2011 & $-3.5^{\star}$ \\
\hline including: atherosclerosis (170) & 1999-2011 & $-4.3^{*}$ & $1999-2011$ & $-4.1^{*}$ \\
\hline \multirow{2}{*}{ Other forms of heart disease (I30-I52) } & \multirow{2}{*}{ 1999-2011 } & \multirow{2}{*}{$1.9^{*}$} & 1999-2002 & -6.9 \\
\hline & & & $2002-2011$ & $3.3^{*}$ \\
\hline \multirow{2}{*}{ Including: heart failure (150) } & 1999-2002 & -10.3 & 1999-2002 & -15.3 \\
\hline & $2002-2011$ & $10.8^{\star}$ & $2002-2011$ & $10.9^{*}$ \\
\hline Malignant neoplasm of stomach (C16) & 1999-2011 & $-2.9^{*}$ & 1999-2011 & $-3.1^{*}$ \\
\hline Malignant neoplasm of colon (C18) & $1999-2011$ & 0.8 & $1999-2011$ & $-1.1^{*}$ \\
\hline Malignant neoplasm of pancreas (C25) & 1999-2011 & 0.2 & 1999-2011 & $-1.2^{*}$ \\
\hline \multirow{3}{*}{ Malignant neoplasm of trachea, bronchus and lung (C33-C34) } & 1999-2001 & 3.5 & \multirow{3}{*}{ 1999-2011 } & \multirow{3}{*}{$3.1^{*}$} \\
\hline & $2001-2009$ & $-1.8^{*}$ & & \\
\hline & $2009-2011$ & -4.9 & & \\
\hline \multirow{2}{*}{ Malignant neoplasm of prostate (C61) } & 1999-2002 & 9.6 & & \\
\hline & 2002-2011 & $-2.5^{*}$ & & \\
\hline Malignant neoplasm of breast (C50) & & & $1999-2011$ & 0.3 \\
\hline Malignant neoplasm of cervix uteri (C53) & & & 1999-2011 & $-1.9^{*}$ \\
\hline Malignant neoplasm of ovary (C56) & & & $1999-2011$ & 0.5 \\
\hline Transport accidents (V01-V99) & 1999-2011 & $-4.1^{*}$ & 1999-2011 & -2.7 \\
\hline Intentional self-harm (X60-X84) & 1999-2011 & $1.4^{*}$ & $1999-2011$ & -0.5 \\
\hline Influenza and pneumonia (J10-J18) & $1999-2001$ & $-2.9^{*}$ & 1999-2011 & $-5.8^{*}$ \\
\hline \multirow{2}{*}{ Chronic lower respiratory diseases (J40-J47) } & 1999-2009 & 1.0 & \multirow{2}{*}{ 1999-2011 } & \multirow{2}{*}{1.2} \\
\hline & $2009-2011$ & $-19.4^{*}$ & & \\
\hline \multirow{3}{*}{ Fibrosis and cirrhosis of liver and alcoholic liver disease (K74, K70) } & 1999-2003 & $-7.9^{*}$ & 1999-2003 & -7.2 \\
\hline & $2003-2007$ & $14.3^{*}$ & $2003-2006$ & 19.1 \\
\hline & $2007-2011$ & $-9.7^{\star}$ & $2006-2011$ & -3.7 \\
\hline
\end{tabular}

${ }^{*} \mathrm{p}<0.05$

Malignant neoplasms belong to the second class of diseases contributing to the highest number of years of life lost. Although deaths caused by malignant neoplasms constituted $22.1 \%$ of the total number of deaths in the Lodz Province in 2011, the percentage of years of life lost due to malignant neoplasms was higher (24.7\%). The difference results mainly from premature female mortality: malignant neoplasms are the most serious life hazard in females aged 30 to 69 years living in the Lodz Province and also in Poland. Of all malignancies, the most serious were malignant neoplasms of the trachea, bronchus and lung, which contributed to an increase in the number of years of life lost in females. Currently, a decrease in the number of males affected by lung cancer, together with a rapid increase in the number of affected females, can be seen in the populations of Poland and Western Europe (24-27), and 2007 was the first year when the number of deaths caused by malignant neoplasms of the trachea, bronchus and lung in female inhabitants of Poland overtook those caused by breast cancer (28). Similar trends were noted with regard to the number of years of life lost by the female inhabitants of the Lodz Province. This increase in the number of deaths due to tracheal, bronchial and lung malignant neoplasms is doubtlessly closely related to heavy smoking. Poland and new member states of the European Union display negative tendencies with respect to smoking by young people, particularly young girls. Although 
$27 \%$ of young males and $13 \%$ of young females were smokers during the mid-nineties, by 2000 , the percentage of girls had risen to $20 \%$ while the percentage of boys smoking remained constant (29). If this negative trend continues, further increases in mortality and the number of lost years of life due to this class of neoplasms can be expected.

Although breast malignancies have been displaced from the first position on the list of causes contributing to the greatest number of years of life lost, they still constitute a serious lifethreatening factor for females. Mortality due to breast cancer for younger women living in Poland is higher than for those in other European countries (30). According to prognosis, the mortality due to these neoplasms will increase over the next decades (31).

External causes pose the most serious life hazard for people aged 5-44 years and contribute to the greatest number of years of life lost calculated per number of people deceased due to a particular reason. The most worrying of the external causes is that of male suicide attempts, with the SEYLL measure growing at an average annual pace of $1.4 \%$ during the period 1999-2011 $(\mathrm{p}<0.05)$. In contrast, the trend was slightly falling in the female group ( $\mathrm{APC}=-0.5, \mathrm{p}>0.05)$, resulting in a $5: 1$ male-to-female suicide rate, which was one of the highest in Europe (32). Males are known to be more at risk of suicide. They are affected by "male depression syndrome", are more prone to stress and alcohol abuse, and are less willing to seek help (33). This is particularly apparent in Central European countries, where many men do not rate their employment prospects high and they feel, or even become, socially excluded by social and economic transformations and increased unemployment (34). Women are less frequently affected by those negative processes as they tend to feel they must be responsible for their children, not hesitate to ask for help, not get involved in risky behaviours, and are less likely to abuse alcohol (35).

\section{Limitations of the Study}

The reliability of statistical analysis on the basis of deaths depends to a large extent on the correct identification of the primary death cause, in particular among the elderly and due to diseases that are the most common causes of death among people in this age group as heart failure or artherosclerosis. Taking that in consideration, certain changes were introduced in Poland in 2009. In order to standardize death causes, which are subject to further statistical analyses, it was determined that the doctor who pronounces death is responsible for filling in the death certificate stating the primary, secondary and direct death cause, whereas qualified teams of doctors are responsible for coding death causes according to the ICD-10 classification. The duties of a dozen of regional statistical offices were taken over by the Polish Central Statistical Office. The relatively short time that the new system of processing data on deaths has been operating impedes its evaluation.

\section{CONCLUSIONS}

The number of years of life lost as calculated per number of the inhabitants of the Lodz Province has been decreasing in the group of males since 2007 and in the group of females since 2009. De- creased mortality due to ischaemic heart disease, including acute myocardial infarction, has contributed to the decrease. In both, males and females, the rate of years of life lost due to cerebral diseases, diseases of the arteries, arterioles and capillaries (mainly atherosclerosis), gastric malignancies, pneumonia and influenza significantly decreased. Negative trends in females mostly refer to the number of years of life lost due to heart failure, tracheal, bronchial and lung malignant neoplasms. In males these trends refer to suicide.

A further decrease in mortality due to cardiovascular diseases might become beneficial as it would reduce the number of premature deaths. Moreover, from the economic point of view, the most effective preventive activities are those aimed at reducing a great number of years of life lost at productive age per one death due to a particular reason, i.e. road traffic accidents, suicides, cirrhosis of the liver and alcoholic liver disease as well as malignant neoplasms of the trachea, bronchi and lungs for both genders, pancreatic neoplasms, neoplasms of the large intestine and gastric malignancies in males and malignant neoplasms of the cervix, ovary and breast in females.

\section{Conflict of Interests}

None declared

\section{Acknowledgement}

The project was financed by the National Science Centre (Decision no. DEC-2013/11/B/HS4/00465).

\section{REFERENCES}

1. Maniecka-Bryła I, Dziankowska-Zaborszczyk E, Bryła M, Drygas W. Determinants of premature mortality in a city population: an eight-year observational study concerning subjects aged 18-64. Int J Occup Med Environ Health. 2013 Oct;26(5):724-41.

2. Maniecka-Bryła I, Pikala M, Bryła M. Health inequalities among rura and urban inhabitants of Łódź Province, Poland. Ann Agric Environ Med. 2012;19(4):723-31.

3. Dziankowska-Zaborszczyk E, Bryła M, Maniecka-Bryła I. The impact of smoking tobacco and drinking alcohol on mortality risk in people of working age -results of an 8-year study in a large urban center. Med Pr. 2014;65(2):251-60. (In Polish.)

4. Rywik SL, Piotrowski W, Rywik TM, Broda G, Szcześniewska D. Is the decrease of cardiovascular mortality in Poland associated with the reduction of global cardiovascular risk related to changes in life style? Kardiol Pol. 2003 May;58(5):344-55. (In Polish.)

5. Central Statistical Office of Poland. Local Data Bank [Internet]. Warsaw: Central Statistical Office of Poland; c2016 [cited 2014 May 15]. Available from: https://bdl.stat.gov.pl/BDL/dane/tablica.

6. United Nations Economic Commission for Europe. Statistical Database [Internet]. Geneva: UNECE [cited 2014 June 23]. Available from: http:// w3.unece.org/pxweb/Dialog/.

7. World Health Organization. European health for all database (HFA-DB) [Internet]. Geneva: WHO [cited 2014 March 2]. Available from: http:// data.euro.who.int $/ \mathrm{hfadb} /$.

8. Eurostat [Internet]. Luxembourg [cited 2014 May 23]. Available from: http://ec.europa.eu/eurostat/data/database.

9. Murray CJL, Lopez AD. The global burden of disease: a comprehensive assessment of mortality and disability from diseases, injuries, and risk factors in 1990 and projected to 2020. Global burden of disease, vol. 1. Kraków: Vesalius; 2000. (In Polish.)

10. Marshall RJ. Standard expected years of life lost as a measure of disease burden: an investigation of its presentation, meaning and interpretation. In: Preedy VR, Watson RR, editors. Handbook of disease burdens and quality of life measures. Berlin: Springer; 2009. p. 3421-34. 
11. Murray CJ, Ezzati M, Flaxman AD, Lim S, Lozano R, Michaud C, et al. GBD 2010: design, definitions, and metrics. Lancet. 2012 Dec 15;380(9859):2063-6.

12. Penner D, Pinheiro P, Krämer A. Measuring the burden of disease due to premature mortality using Standard Expected Years of Life Lost (SEYLL) in North Rhine-Westphalia, a Federal State of Germany, in 2005. J Public Health. 2010;18(4):319-25.

13. Gènova-Maleras R, Catalá-López F, de Larrea-Baz NF, Álvarez-Martín E, Morant-Ginestar C. The burden of premature mortality in Spain using standard expected years of life lost: a population-based study. BMC Public Health. 2011 Oct 11;11:787. doi: 10.1186/1471-2458-11-787.

14. Vlajinac H, Marinkovic J, Kocev N, Sipetic S, Bjegovic V, Jankovic S, et al. Years of life lost due to premature death in Serbia (excluding Kosovo and Metohia). Public Health. 2008 Mar;122(3):277-84.

15. Eurostat. Health statistics - atlas on mortality in the European Union Luxembourg: Office for Official Publications of the European Communities; 2009.

16. Kim HJ, Fay MP, Feuer EJ, Midthune DN. Permutation tests for joinpoint regression with applications to cancer rates. Stat Med. 2000 Feb $15 ; 19(3): 335-51$.

17. Bandosz P, O'Flaherty M, Drygas W, Rutkowski M, Koziarek J, Wyrzykowski B, et al. Decline in mortality from coronary heart disease in Poland after socioeconomic transformation: modelling study. BMJ. 2012 Jan 25;344:d8136. doi: 10.1136/bmj.d8136.

18. Maniecka-Bryła I, Maciak-Andrzejewska A, Bryła M, Bojar I. An assessment of health effects of a cardiological prophylaxis programme in a local community with the use of the SCORE algorithm. Ann Agric Environ Med. 2013;20(4):794-9.

19. Sapiński W, Drygas W, Gerstenkorn A, Klimczak A, Niełacny K, Pikala $M$. Influence of place of residence on prevalence of risk factors for cardiovascular diseases. Kardiol Pol. 1999;50:111-6.

20. Jasiński B. Contribution of the decrease in coronary heart disease mortality rate to the decrease in the total mortality rate in Poland. Zdrow Publiczne. 2008;118(1):36-43

21. Gerber Y, Jacobsen SJ, Frye RL, Weston SA, Killian JM, Roger VL. Secular trends in deaths from cardiovascular diseases: a 25-year community study. Circulation. 2006 May 16;113(19):2285-92.

22. Amiri M, Janssen F, Kunst AE. The decline in ischaemic heart disease mortality in seven European countries: exploration of future trends. $\mathrm{J}$ Epidemiol Community Health. 2011 Aug;65(8):676-81.

23. Maniecka-Bryła I, Pikala M, Bryła M. Life years lost due to cardiovascular diseases. Kardiol Pol. 2013;71(10):1065-72.

24. Bray F, Tyczynski JE, Parkin DM. Going up or coming down? The changing phases of the lung cancer epidemic from 1967 to 1999 in the 15 European Union countries. Eur J Cancer. 2004 Jan;40(1):96-125

25. Didkowska J, Manczuk M, McNeill A, Powles J, Zatonski W. Lung cancer mortality at ages 35-54 in the European Union: ecological study of evolving tobacco epidemics. BMJ. 2005 Jul 23;331(7510):189-91.

26. Levi F, Lucchini F, Negri E, La Vecchia C. Trends in mortality from major cancers in the European Union, including acceding countries, in 2004. Cancer. 2004 Dec 15;101(12):2843-50.

27. Pikala M, Maniecka-Bryla I. Years of life lost due to malignant neoplasms characterized by the highest mortality rate. Arch Med Sci. 2014 Oct 27;10(5):999-1006.

28. Didkowska J, Wojciechowska U, Zatoński W. Cancer in Poland in 2007. Warsaw: Maria Sklodowska-Curie Memorial Cancer Centre - Institute of Oncology; 2009. (In Polish.)

29. Tyczynski JE, Bray F, Aareleid T, Dalmas M, Kurtinaitis J, Plesko I, et al Lung cancer mortality patterns in selected Central, Eastern and Southern European countries. Int J Cancer. 2004 Apr 20;109(4):598-610.

30. Malvezzi M, Bertuccio P, Levi F, La Vecchia C, Negri E. European cancer mortality predictions for the year 2012. Ann Oncol. 2012 Apr;23(4):104452.

31. Didkowska J, Wojciechowska U, Zatoński W. Prediction of cancer incidence and mortality in Poland up to the year 2025. Warsaw: Maria Sklodowska-Curie Memorial Cancer Centre - Institute of Oncology; 2009. (In Polish, English.)

32. Möller-Leimkühler AM. The gender gap in suicide and premature death or: why are men so vulnerable? Eur Arch Psychiatry Clin Neurosci. 2003 Feb;253(1):1-8

33. Pikala M, Bryla M, Bryla P, Maniecka-Bryla I. Years of life lost due to external causes of death in the Lodz province, Poland. PLoS One. 2014 May 8;9(5):e96830. doi: 10.1371/journal.pone.0096830.

34. Wålinder J, Rutzt W. Male depression and suicide. Int Clin Psychopharmacol. 2001 Mar;16 Suppl 2:S21-4.

35. Oquendo MA, Bongiovi-Garcia ME, Galfalvy H, Goldberg PH, Grunebaum MF, Burke AK, et al. Sex differences in clinical predictors of suicidal acts after major depression: a prospective study. Am J Psychiatry. 2007 Jan;164(1):134-41 